\title{
Anatomical Correlates of Neuropsychological Deficits Among Patients With the Cerebellar Stroke
}

\author{
Min A Shin, MD, Oak Tae Park, MA, Joon-Ho Shin, MD, MS \\ Department of Rehabilitation Medicine, National Rehabilitation Center, Seoul, Korea
}

\begin{abstract}
Objective To investigate the anatomical correlates of the neuropsychological deficits in patients with the cerebellar stroke.

Methods We screened patients who were admitted to the National Rehabilitation Center with the cerebellar stroke between October 2012 and November 2016. The patients with the cerebellar stroke who underwent neuropsychological testing for which the Seoul Neuropsychological Screening Battery (SNSB) or the SNSB-II were enrolled. The neuropsychological function capacities were compared in accordance with the stroke type (hemorrhagic vs. ischemic) and the location (right/left anterior, right/left posterior intermediate, right/left posterior lateral lobe, and vermis). Mean z-scores were computed to compare the patient performances with the population averages.

Results Twenty-six patients ( 15 with ischemic stroke and 11 with hemorrhagic stroke) with a mean age of $54.8 \pm 16.6$ years were assessed $8.8 \pm 9.2$ months after the stroke. Differences in the neuropsychological functioning according to the stroke type were not observed. All of the numerical subtests of the stroke patients showed significantly poorer performances compared with the population averages (mean z-score $<0$ ), and some of the subtests revealed abnormal performances in attention-, visuospatial function-, memory-, and frontal/executive function-related tasks (mean z-score $<-1$ ). The patients with the presence of a lesion in the right posterior intermediate lobe of the cerebellum showed a poorer performance in the subtests evaluating the executive function including the Korean-version Stroop Test $(\mathrm{p}=0.04)$, the Digit Symbol Coding Test $(\mathrm{p}=0.01)$, and the Korean-version Trail Making Test $(\mathrm{p}=0.02)$ compared with the patients without that lesion.

Conclusion The present study confirms that the cerebellar stroke affects the neuropsychological functioning which is associated with the anatomical site of stroke.
\end{abstract}

Keywords Stroke, Cerebellum, Cognition, Executive function

Received April 14, 2017; Accepted May 23, 2017

Corresponding author: Joon-Ho Shin

Department of Rehabilitation Medicine, National Rehabilitation Center, 58 Samgaksan-ro, Gangbuk-gu, Seoul 01022, Korea. Tel: +82-2-901-1884, Fax: +82-2-901-1899, E-mail: asfreelyas@gmail.com

ORCID: Min A Shin (http://orcid.org/0000-0002-1085-6000); Oak Tae Park (http://orcid.org/0000-0001-9063-0521); Joon-Ho Shin (http://orcid. org/0000-0001-6447-8829).

(c) This is an open-access article distributed under the terms of the Creative Commons Attribution Non-Commercial License (http://creativecommons.org/ licenses/by-nc/4.0) which permits unrestricted noncommercial use, distribution, and reproduction in any medium, provided the original work is properly cited. Copyright $\odot 2017$ by Korean Academy of Rehabilitation Medicine 


\section{INTRODUCTION}

While the cerebellum is principally associated with motor control and coordination, recent research has identified a broad range of neuropsychological deficits that may occur following a localized cerebellar pathology including deficits in attention, the working memory, language, visuospatial processing, planning, and abstract reasoning $[1,2]$. This broad range of cerebellar-damageassociated symptoms have been collectively termed 'cerebellar cognitive affective syndrome' [3]. Discrete regions of the cerebellum appear to mediate different neuropsychological functions, as revealed by both lesion- and functional-neuroimaging studies. These studies attribute the neuropsychological functions to the posterior region of the cerebellar cortex, while the emotional and neuropsychiatric functions are attributed to the medial region [4]. More specifically, the lesions of the right cerebellar hemisphere produce deficits in the verbal memory and language, whereas the lesions of the left cerebellar hemisphere lead to visuospatial processing deficits [5-7].

The exact cerebellum-function organization, however, is not easily ascertained from clinical cases involving extracerebellar pathology or mixed pathology cases including cerebellitis, tumors, and arteriovenous malformations. Although researches on patients with only focal cerebellar infarctions have been conducted, the results from these studies include inconsistent or limited results regarding the frontal executive dysfunction and its location in the cerebellum $[1,6,8]$. Thus, it is necessary to obtain an improved functional neuroanatomy mapping of the cerebellum.

The aim of this study is the examination of the neuropsychological deficits in homogenous groups of patients with the cerebellar stroke using comprehensive neuropsychological testing. First, a comparison of the neuropsychological functions between the types of stroke lesion (hemorrhagic vs. ischemic) was performed. Then, the subtest results from the cerebellar stroke patients were compared with the population averages. Finally, the results of each neuropsychological subtest were analyzed based on the presence or absence of a discrete lesion location.

\section{MATERIALS AND METHODS}

\section{Patients}

All of the cerebellar stroke patients who were admitted to the Department of Rehabilitation Medicine in the National Rehabilitation Center between October 2012 and November 2016 were screened as potential candidates of the present study. The inclusion criteria are as follows: (1) cerebellar stroke confirmed via neuroimaging (brain computed tomography [CT] or magnetic resonance imaging [MRI]) and a neurological examination; (2) firsttime stroke; and (3) completion of neuropsychological testing. The exclusion criteria are as follows: (1) any disorder of consciousness (vegetative state or minimally conscious state), or (2) history of a neuropsychological or neurological disorder that was diagnosed prior to the stroke. The study protocol was approved by the Institutional Review Board of the Department of Rehabilitation Medicine at the National Rehabilitation Center (IRB No. NRC-2017-03-019).

\section{Neuropsychological evaluation}

The Seoul Neuropsychological Screening Battery (SNSB) or the SNSB-II was used for the neuropsychological evaluations. These batteries evaluate the five neuropsychological domains of attention, language, visuospatial functioning, memory, and frontal executive functioning. The SNSB-II includes the following subtests in addition to those of the original SNSB: Vigilance Test, Clock Drawing Test, Digit Symbol Coding (DSC) test, and Korean Trailing Making Test (K-TMT). The SNSB and SNSB-II subsets are grouped according to these major functional categories $[9,10]$.

The SNSB and/or SNSB-II subtests yielded three different types of data as follows. First, the results with numeric continuous values were converted to z-scores. This approach was applied to the Digit Span Test (DST; forward and backward), the Rey Complex Figure Test (RCFT; copy score, copy time, immediate recall, delayed recall, and recognition), the Seoul Verbal Learning Test (SVLT; immediate recall, delayed recall, and recognition), the semantic (animal, supermarket) and phonemic $(\neg, \circ, \lambda)$ components of the Controlled Oral WordAssociation Test (COWAT), the color reading in the Korean Color-Word Stroop Test (K-CWST), the DSC test, and the K-TMT. Second, the results with categorical variables 
were divided based on the percentiles $(<5$ th, 5 th-10th, 10th-15th, and $>15$ th). This approach was applied to the Repetition Test, Calculation Test, Ideomotor Praxis Test, Clock Drawing Test, Contrasting Program Test, Go/No-go task, and the K-CWST word-reading component. Third, the categorical dichotomous data were categorized to be reflective of a normal or an abnormal performance. This approach was applied to a vigilance test, letter cancellation test, spontaneous speech test (fluency and contents), comprehension, reading, writing, finger naming test, right-left orientation test, body-part identification test, buccofacial praxis test, fist-edge/palm test, alternating hand-movement test, alternating square and triangle test, and the Luria loop test.

For the statistical comparisons, raw scores from 14 patients who had been evaluated using the SNSB prior to the publication of the SNSB-II were converted into novel values based on the presented criteria in the SNSB-II. Six patients below the age of 45 years were standardized to 45 years and the education criteria described in the SNSB-II [10].

The z-scores were standardized using the age and the educational criteria that are presented in the SNSBII based on a large, nationwide Korean sample $(1,100$ people), thereby making it possible to make comparisons with the population averages. A $\mathrm{z}$-score $<0$ indicates a poorer performance relative to the population average, while a z-score $<-1$ indicates an abnormal performance, as suggested by the SNSB-II criteria. The categorical results below the 15th percentile were also considered as indicative of an abnormal performance [10]. With these conversions, the whole variables were recategorized into dichotomous variables (i.e., normal or abnormal performance) for a further statistical analysis.

\section{Stroke types and the lesion localization}

Brain CT or MRI findings were reviewed for all of the patients. The type of stroke lesion (hemorrhagic or ischemic) was recorded, and the lesion location was categorized as follows: right anterior, left anterior, right posterior intermediate, left posterior intermediate, right posterior lateral, left posterior lateral, or vermis (Fig. 1). In the patients whose lesions spanned more than one location due to the nature of disease progression, each lesion location was recorded as a dichotomous variable (i.e., presence or absence).

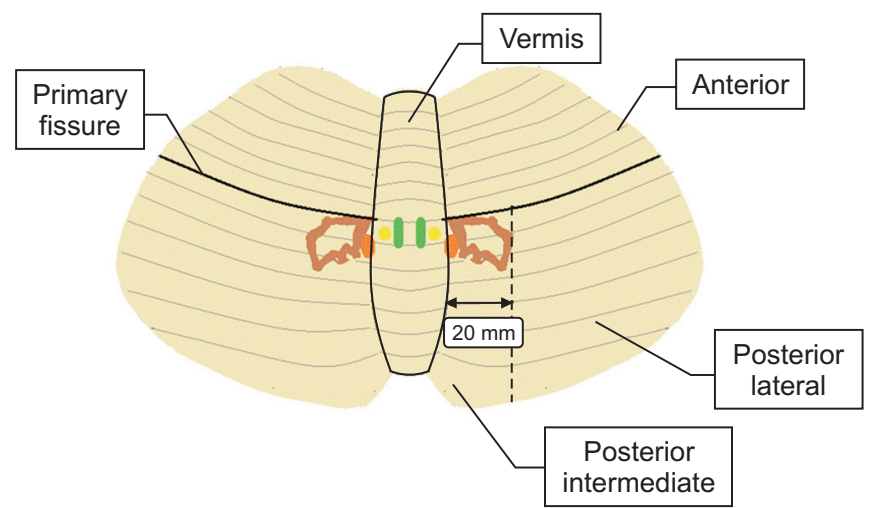

Fig. 1. Schematic representation of the subdivisions of the cerebellum.

The lesion location is fundamentally based on the cerebellar anatomy, as follows: The cerebellum consists of the vermis and two large cerebellar hemispheres, which are divided into anterior and posterior lobes by the primary fissures [11]. The posterior lobe was further subdivided based on the presence of deep cerebellar nuclei that project to a wider variety of supratentorial regions [12]. The location, size, and shape of the deep cerebellar nuclei including the dentate nucleus have been described in several previous studies [13-15]. Based on the findings of these previous reports, the region from the midline to the 20-mm lateral to the posterior lobe was designated as 'posterior intermediate lobe'; the remaining lateral area of the posterior lobe was designated as 'posterior lateral lobe'.

\section{Statistical analysis}

SPSS software ver. 21.0 (IBM, Armonk, NY, USA) was used for all of the analyses of the present study. Student t-tests and the Mann-Whitney U-test were used to compare the continuous variables. Continuous neuropsychological variables were converted to z-scores to identify the poorer performances among the cerebellar-stroke patients compared with the population averages (Onesample t-test). Chi-squared $\left(\chi^{2}\right)$ tests and the Fisher exact test were used to identify the anatomical correlates of the neuropsychological deficits. These $2 \times 2$ tests were used to analyze the dichotomous results of the neuropsychological subtests based on the presence or absence of specific lesion locations. The data are expressed as the mean \pm standard deviation. The level of statistical significance was set at $\mathrm{p}<0.05$. 


\section{RESULTS}

\section{Clinical and neuropsychological characteristics}

Twenty-six stroke patients (11 patients with the hemorrhagic stroke and 15 patients with the ischemic stroke) of a mean age of $54.8 \pm 16.6$ years were enrolled in the present study. The neuropsychological functioning was assessed over a post-stroke mean duration of $8.8 \pm 9.2$ months. Fourteen patients presented with bilateral cerebellar lesions, 7 patients presented with right-side lesions, and 5 patients presented with left-side lesions. All of the patients were right-handed. The demographics and clinical findings are summarized in Table 1.

A comparison between the results of the patient neuropsychological subtests regarding the hemorrhagic and ischemic cerebellar strokes was performed to evaluate the potential differences in the patterns of the neuropsychological deficits between the two groups. Significant intergroup differences, however, are not evident (Table 2).

The mean z-scores from all of the subtests with the continuous data are $<0$, indicating poorer performances in the cerebellar-stroke patients compared with the population averages. The subtest $\mathrm{z}$-scores of the attention (forward DST), visuospatial functioning (RCFT copy score and time), memory (immediate- and delayed-recall values in the SVLT), and frontal executive functioning (semantic and phonemic subtests of the COWAT, K-CWST color reading, DSC test, and Trail A of the K-TMT) are $<-1$, indicating an abnormal performance (Table 3 ). All of

Table 1. Demographics and clinical findings of the subjects $(n=26)$

\begin{tabular}{|lc|}
\hline \multicolumn{1}{|c}{ Characteristic } & Value \\
\hline Age (yr) & $54.8 \pm 16.6$ \\
\hline Duration after onset (mo) & $8.8 \pm 9.2$ \\
\hline Sex & \\
\hline Male & 17 \\
\hline Female & 9 \\
\hline Type of stroke & 11 \\
\hline Hemorrhagic & 15 \\
\hline Ischemic & $26.0 \pm 4.4$ \\
\hline K-MMSE score
\end{tabular}

Values are presented as mean \pm standard deviation or number.

K-MMSE, Korean version of Mini-Mental Status Examination. these results are statistically significant. Table 4 shows the results of the categorical dichotomous neuropsychological subtests for all of the 26 patients.

Correlations between the cerebellar lesion location and the cognitive functioning

In this study, the presence of a lesion in the rightposterior-intermediate lobe of the cerebellum is associated with poorer performances on the word-reading components of the K-CWST ( $\mathrm{p}=0.04)$, DSC test $(\mathrm{p}=0.01)$, and Trail A of the K-TMT ( $\mathrm{p}=0.02)$ that assess the frontal executive functioning. The presence of a lesion in the right posterior lateral of the cerebellum is associated with a poorer performance on the immediate-recall portion of the SVLT $(p=0.04)$ relative to the patients without such lesions (Table 5). Significant associations were not observed for any of the other neuropsychological subtest scores.

\section{DISCUSSION}

The present study confirms that the cerebellar stroke affects the neuropsychological functioning based on the affected anatomical site. Significant differences in the neuropsychological deficits were not observed between the patients with the hemorrhagic stroke versus those with the ischemic cerebellar stroke. The heterogeneity of the cerebellum lesion types has been noted as a limitation in many previous studies [3,16-18], although only a few studies have investigated the neuropsychological deficits after the cerebellar stroke in accordance with the lesion type. The results here suggest that the lesion location, rather than the type of stroke, is more important regarding the neuropsychological impairments in cerebellar stroke patients.

Neuropsychological functioning deficits following cerebellar damage have been reported in the literature. Such impairments have been noted with regard to the executive functioning (planning, set-shifting, abstract reasoning, verbal fluency, and working memory), visuospatial functioning, and language [3]. The results of this study are consistent with those previous findings. The z-scores that were calculated from the patient subtest results showed poorer performances compared with the population averages. In particular, the tasks evaluating the attention, visuospatial functioning, memory, and frontal 
Min A Shin, et al.

Table 2. Comparison of neuropsychological subtests according to the type of stroke lesion after the cerebellar stroke

\begin{tabular}{|c|c|c|c|c|c|}
\hline & & & $\begin{array}{l}\text { Hemorrhagic } \\
(n=11)\end{array}$ & $\begin{array}{l}\text { Ischemic } \\
(n=15)\end{array}$ & p-value ${ }^{a)}$ \\
\hline \multirow[t]{4}{*}{ Attention } & Digit Span & Forward & $-0.42 \pm 1.38$ & $-0.59 \pm 1.24$ & 0.76 \\
\hline & & Backward & $-0.81 \pm 1.51$ & $-0.90 \pm 0.96$ & 0.86 \\
\hline & Vigilance test & & 0 & 15 & 0.23 \\
\hline & Letter cancelation & & 33 & 29 & 0.85 \\
\hline \multirow{12}{*}{$\begin{array}{l}\text { Language and related } \\
\text { functions }\end{array}$} & Spontaneous speech & Fluency & 22 & 17 & 1.00 \\
\hline & & Contents & 11 & 0 & 0.59 \\
\hline & Comprehension & & 20 & 0 & 0.27 \\
\hline & Repetition & & 30 & 0 & 0.07 \\
\hline & Reading & & 9 & 0 & 0.42 \\
\hline & Writing & & 18 & 7 & 0.56 \\
\hline & Finger naming & & 30 & 25 & 0.74 \\
\hline & Right-left orientation & & 25 & 0 & 0.27 \\
\hline & Body-part identification & & 10 & 0 & 0.75 \\
\hline & Calculation & & 40 & 43 & 1.00 \\
\hline & Praxis & Ideomotor & 10 & 31 & 0.34 \\
\hline & & Buccofacial & 0 & 0 & 1.00 \\
\hline \multirow[t]{3}{*}{ Visuospatial functioning } & Rey Complex Figure Test & Copy score & $-5.85 \pm 6.71$ & $-4.17 \pm 6.45$ & 0.54 \\
\hline & & Copy time & $-0.59 \pm 1.41$ & $-0.35 \pm 1.40$ & 0.68 \\
\hline & Clock Drawing Test & & 43 & 50 & 1.00 \\
\hline \multirow[t]{6}{*}{ Memory } & Seoul Verbal Learning Test & Immediate recall & $-1.70 \pm 1.87$ & $-1.55 \pm 1.03$ & 0.79 \\
\hline & & Delayed recall & $-1.63 \pm 1.35$ & $-1.69 \pm 1.32$ & 0.91 \\
\hline & & Recognition & $-0.94 \pm 1.65$ & $-2.02 \pm 1.88$ & 0.14 \\
\hline & Rey Complex Figure Test & Immediate recall & $-0.72 \pm 1.30$ & $-1.37 \pm 1.23$ & 0.26 \\
\hline & & Delayed recall & $-0.75 \pm 1.50$ & $-1.58 \pm 1.55$ & 0.25 \\
\hline & & Recognition & $-1.08 \pm 1.88$ & $-0.95 \pm 1.96$ & 0.88 \\
\hline \multirow[t]{14}{*}{$\begin{array}{l}\text { Frontal/executive } \\
\text { functions }\end{array}$} & $\begin{array}{l}\text { Controlled Oral } \\
\text { Word-Association Test }\end{array}$ & Animal & $-1.53 \pm 1.53$ & $-1.86 \pm 1.00$ & 0.53 \\
\hline & & Supermarket & $-2.04 \pm 0.98$ & $-1.45 \pm 0.97$ & 0.17 \\
\hline & & $\neg$ & $-1.11 \pm 1.27$ & $-1.57 \pm 0.83$ & 0.41 \\
\hline & & 0 & $-1.10 \pm 1.27$ & $-1.57 \pm 0.83$ & 0.29 \\
\hline & & 入 & $-1.10 \pm 1.27$ & $-1.57 \pm 0.83$ & 0.29 \\
\hline & & Phonemic total & $-1.30 \pm 1.43$ & $-1.48 \pm 1.48$ & 0.78 \\
\hline & & Animal $+\neg$ & $-1.54 \pm 1.65$ & $-2.12 \pm 1.09$ & 0.33 \\
\hline & $\begin{array}{l}\text { Korean Color-Word Stroop } \\
\text { Test }\end{array}$ & Color reading & $-1.43 \pm 1.63$ & $-2.33 \pm 1.76$ & 0.30 \\
\hline & Digit Symbol Coding & & $-2.02 \pm 1.92$ & $-2.55 \pm 1.50$ & 0.60 \\
\hline & Korean Trail Making Test & Trail A & $-9.56 \pm 15.14$ & $-3.36 \pm 3.91$ & 0.30 \\
\hline & & Trail B & $-3.41 \pm 4.78$ & $-1.98 \pm 1.90$ & 0.51 \\
\hline & Motor impersistence & & 0 & 0 & 1.00 \\
\hline & Contrasting program & & 22 & 46 & 0.38 \\
\hline & Go-No Go & & 33 & 54 & 0.42 \\
\hline
\end{tabular}


Table 2. Continued

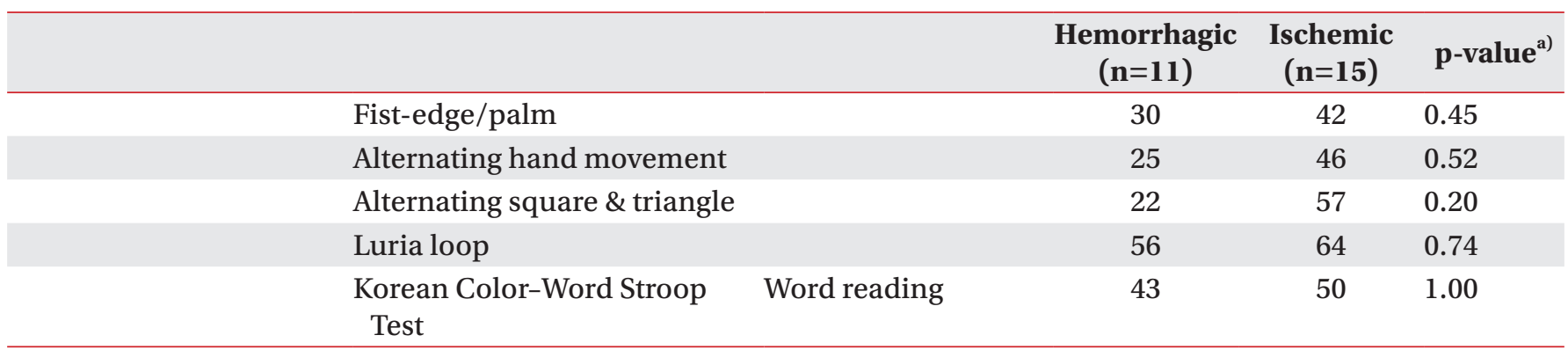

Values are presented as the mean \pm standard deviation (z-score) or the percentage of patients with an abnormal performance.

${ }^{a)} \mathrm{p}$-value by the Student t-test or the Mann-Whitney U-test for the numeric neuropsychological subtests, or the $\chi^{2}$ test or the Fisher exact test for the categorical dichotomous neuropsychological subtests.

Table 3. Z-scores of numeric neuropsychological subtests in patients with the cerebellar stroke $(n=26)$

\begin{tabular}{|c|c|c|c|c|c|}
\hline & & & Mean+SD & p-vi & alue \\
\hline & & & vieantsD & $\mathrm{z}$-score $<\mathbf{0}^{\mathrm{a})}$ & z-score $<-\mathbf{1}^{\text {b) }}$ \\
\hline Attention & Digit Span & Forward & $-0.52 \pm 1.27$ & $0.029^{*}$ & $0.040^{*}$ \\
\hline & & Backward & $-0.86 \pm 1.19$ & $0.001^{*}$ & 0.285 \\
\hline Visuospatial functioning & Rey Complex Figure Test & Copy score & $-4.87 \pm 6.47$ & $0.001^{*}$ & $0.004^{*}$ \\
\hline & & Copy time & $-0.45 \pm 1.38$ & 0.062 & $0.032^{*}$ \\
\hline Memory & Seoul Verbal Learning Test & Immediate recall & $-1.62 \pm 0.41$ & $0.001^{*}$ & $0.018^{*}$ \\
\hline & & Delayed recall & $-1.66 \pm 1.30$ & $0.001^{*}$ & $0.008^{*}$ \\
\hline & & Recognition & $-1.56 \pm 1.84$ & $0.001^{*}$ & 0.066 \\
\hline & Rey Complex Figure Test & Immediate recall & $-1.12 \pm 1.27$ & $0.001^{*}$ & 0.330 \\
\hline & & Delayed recall & $-1.26 \pm 1.54$ & $0.001^{*}$ & 0.224 \\
\hline & & Recognition & $-1.00 \pm 1.88$ & $0.012^{*}$ & 0.498 \\
\hline Executive functions & $\begin{array}{l}\text { Controlled Oral } \\
\text { Word-Association Test }\end{array}$ & Animal & $-1.71 \pm 1.24$ & $0.001^{*}$ & $0.004^{*}$ \\
\hline & & Supermarket & $-1.70 \pm 1.00$ & $0.001^{*}$ & $0.002^{*}$ \\
\hline & & $\neg$ & $-1.32 \pm 1.02$ & $0.001^{*}$ & 0.075 \\
\hline & & 0 & $-1.30 \pm 0.99$ & $0.001^{*}$ & $0.050^{*}$ \\
\hline & & 入 & $-1.37 \pm 1.05$ & $0.001^{*}$ & $0.050^{*}$ \\
\hline & & $\begin{array}{l}\text { Phonemic total } \\
\text { score }\end{array}$ & $-1.40 \pm 1.41$ & $0.001^{*}$ & 0.097 \\
\hline & & Animal $+\neg$ & $-1.86 \pm 1.37$ & $0.001^{*}$ & $0.004^{*}$ \\
\hline & Korean Color-Word Stroop & Color reading & $-1.96 \pm 1.72$ & $0.001^{*}$ & $0.018^{*}$ \\
\hline & Digit Symbol Coding & & $-2.26 \pm 1.69$ & $0.001^{*}$ & $0.010^{*}$ \\
\hline & Korean Trail Making Test & Trail A: total time & $-6.67 \pm 11.46$ & $0.021^{*}$ & $0.038^{*}$ \\
\hline & & Trail B: total time & $-2.75 \pm 3.17$ & $0.010^{*}$ & 0.056 \\
\hline
\end{tabular}

The z-score is a standardized score of each parameter with an age and an educational level that matches those of the general population in Korea.

${ }^{\text {a) }} \mathrm{A}$ z-score $<0$ indicates a poorer performance compared with the population average.

${ }^{b)} \mathrm{A}$ z-score $<-1$ indicates an abnormal performance based on the Seoul Neuropsychological Screening Battery (SNSB-II) criteria.

${ }^{*} \mathrm{p}<0.05$ by the one-sample $\mathrm{t}$-test. 
Table 4. Proportion of patients with an abnormal performance on the categorical dichotomous neuropsychological subtests in patients with the cerebellar stroke $(n=26)$

\begin{tabular}{|c|c|c|c|}
\hline & & & $\%$ \\
\hline \multirow{2}{*}{ Attention } & Vigilance test & & 7 \\
\hline & Letter cancelation & & 30 \\
\hline \multirow[t]{12}{*}{ Language and related functions } & Spontaneous speech & Fluency & 19 \\
\hline & & Contents & 5 \\
\hline & Comprehension & & 9 \\
\hline & Repetition & & 13 \\
\hline & Reading & & 4 \\
\hline & Writing & & 16 \\
\hline & Finger naming & & 27 \\
\hline & Right-left orientation & & 9 \\
\hline & Body-part identification & & 4 \\
\hline & Calculation & & 42 \\
\hline & Praxis & Ideomotor & 22 \\
\hline & & Buccofacial & 0 \\
\hline Visuospatial functioning & Clock Drawing Test & & 46 \\
\hline \multirow[t]{8}{*}{ Frontal/executive functions } & Motor impersistence & & 0 \\
\hline & Contrasting program & & 36 \\
\hline & Go-No Go & & 45 \\
\hline & Fist-edge/palm & & 30 \\
\hline & Alternating hand movement & & 38 \\
\hline & Alternating square $\&$ triangle & & 43 \\
\hline & Luria loop & & 60 \\
\hline & Korean Color-Word Stroop Test & Word reading & 47 \\
\hline
\end{tabular}

executive functioning indicated statistically significant abnormal performances.

It is thought that a network of reciprocal cerebrocerebellar connections comprising both afferent (corticopontine and pontocerebellar) and efferent (cerebellothalamic and thalamocortical) tracts mediates the cerebellar neuropsychological functioning $[5,12]$. Thus, neuropsychological deficits that are secondary to cerebellar damage may be the consequence of a disruption of these connections between the cerebellar and the cerebrum $[3,19,20]$, and this mechanism may explain the different neuropsychological deficits that are indicated by the authors' results. Abnormal performances in the attention, memory (i.e., for ongoing events), and frontal executive tasks may be associated with the disruption of the connections between the cerebellum and the prefrontal and premotor areas of the frontal lobes [1]. An abnormal visuospatial function performance may be as- sociated with the disruption of the connections between the cerebellum and the posterior parietal, temporal, or occipital areas of the brain [1]. Previous studies have also suggested that the dissociation of the frontocortical and frontosubcortical connections-including the parallel circuits that pass through the basal ganglia and the cerebellum-contributes to neuropsychological deficits. The dissociation of the connections with the dorsolateral and inferior prefrontal cortices results in the dysregulation of the attention and the cognitive/inhibitory control, while the connective dissociation regarding the orbital and ventromedial structures results in mood and motivational impairments [21,22].

It suggested that the cognitive impairment in patients with an isolated cerebellar infarct is dependent on the infarct location [1]. Consistent with this idea, it was found in the present study that the patients with lesions in the right posterior intermediate lobe of the cerebellum- 


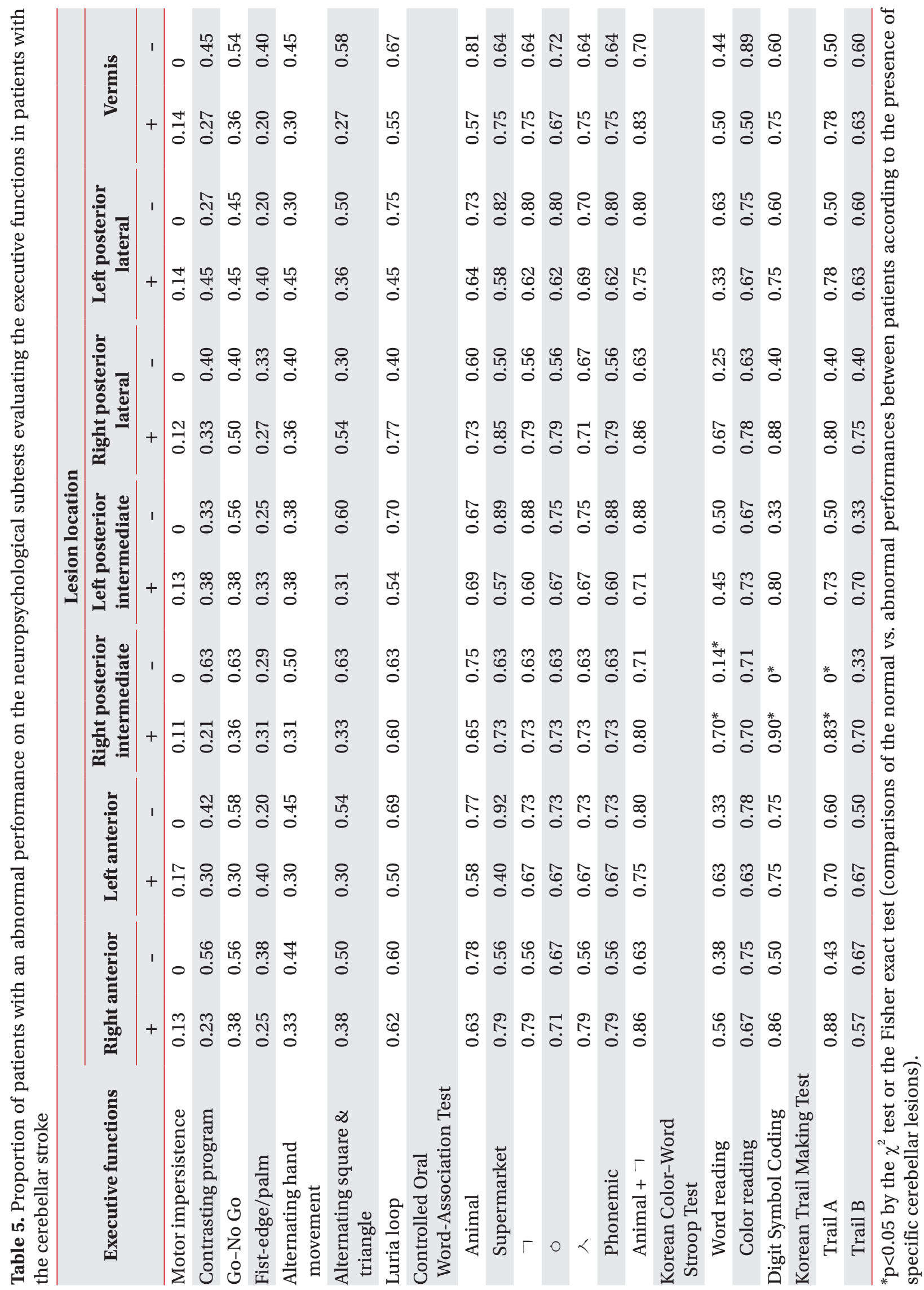


which contains the deep cerebellar nuclei, including the dentate nuclei-more frequently showed abnormal performances on the executive-function neuropsychological subtests than the patients without such lesions. Executive dysfunction has been proposed as the core symptom of a cerebellar lesion $[3,8]$. Functional neuroimaging investigations have demonstrated that a variety of cognitive tasks such as articulatory and phonological processing tasks and the pegboard-puzzle task are associated with metabolic increases, mainly in the cortex of the lower lateral areas and the central parts of the dentate nuclei of the cerebellum [23-26]. Other studies have suggested that the dentate nuclei are associated with neuropsychological processes, particularly the executive functioning [27]. The finding that dentate activation is associated with the activation of the thalamic, striatal, and dorsolateral prefrontal regions also supports the results of this study [28]. Other studies also support the laterality of this effect; that is, damage to the right cerebellar hemisphere produced more pronounced working memory deficits than the damage of the left hemisphere $[16,29]$. Functional MRI and lesion studies have also demonstrated that the working memory and the sequencing that are dependent on the executive processing are associated with the right cerebellar hemisphere $[17,30,31]$. Therefore, the right posterior intermediate lobe of the cerebellum is thought to play a role in executive function.

In the present study, the authors also observed that the patients with the lesions of the right posterior lateral lobe of the cerebellum more frequently exhibited an impaired immediate recall on the SVLT that reflects the holding capacity of the working and verbal memories [32]. This finding is consistent with those of previous studies, thereby demonstrating that the damaging of the right cerebellar hemisphere produces deficits in the working and verbal memories [4].

The present study, however, is affected by a number of noteworthy limitations. First, the approach that was utilized for the lesion localization is somewhat arbitrary. The blood vessel territory in the cerebellum, however, is less appropriate for the lesion localization, as the relative irrigated sizes and territories are not constant, and anastomoses may occur between the terminal branches $[33,34]$; furthermore, a lesion localization that is based on the known cerebellar lobules (lobules I to X) [35] is suboptimal for the capturing of CT images [33]. For these reasons, a subdivision of the cerebellum based on the functional neuroimaging results was performed, thereby demonstrating a wider variety of projections from the deep cerebellar nuclei to the supratentorial regions [12].

The findings of the present paper fail to demonstrate the relationships between the other lesion locations in the cerebellum and specific neuropsychological deficits. The reason for this might be related to the small sample size and the presence of mixed lesions in a majority of the patients. Furthermore, the statistical framework $\left(\chi^{2}\right.$ test and the Fisher exact test) that was used in the present study for the detection of significant neuropsychological deficits cannot achieve a satisfactory statistical power due to the limited assessment of the differential spatial distributions [36]. However, as the locations of the brain damage are not randomly distributed throughout the brain due to the nature of causative disease processes [37], the lesion coverage is inevitably heterogeneous [36]. In addition, it was difficult to perform a voxel-wise analysis in the present study, as the lesion images were obtained via both MRI and CT. For these reasons, the inferential statistics that were used to identify the anatomical correlates of the neuropsychological deficits are the statistical framework in the effective coverage maps, which were defined based on the possible detection of specific deficits (i.e., maps of the maximal lesion-deficit relationships) [36].

Previous studies have indicated that the cerebellum exhibits an ability to recover from pathological insults, with favorable post-lesion neurological and functional outcomes noted at 12 months $[38,39]$. Considering this recovery pattern, the great variability of the duration from the stroke onset to the assessment of the neuropsychological functioning (8.8 \pm 9.2 months) represents another relevant limitation. Further studies are required to more accurately delineate the neuropsychological function domains in the cerebellum.

Nevertheless, to the best of the authors' knowledge, the present study is the first to demonstrate that the presence of stroke lesions in the right-posterior-intermediate lobe of the cerebellum-containing the deep cerebellar nuclei-likely results in executive function impairments. The authors' findings also suggest that the location of the stroke lesions is correlated more to the specific types of neuropsychological deficit than the stroke pathology (hemorrhagic vs. ischemic). Moreover, the present study is the first to utilize a Korean language neuropsychologi- 
cal screening battery for the identification of the cerebellar neuropsychological characteristics.

In conclusion, it is suggested that the neuropsychological deficits in patients with the cerebellar stroke may differ depending on the location of the discrete lesions. Thus, these patients should undergo careful monitoring for specific neuropsychological deficits during the rehabilitation process in order to facilitate the management and the recovery of the deficits.

\section{CONFLICT OF INTEREST}

No potential conflict of interest relevant to this article was reported.

\section{ACKNOWLEDGMENTS}

This study was supported by a grant (No. NRCTRIN15002, NRCTR-IN16002) from the Translational Research Center for Rehabilitation Robots, Korea National Rehabilitation Center, Ministry of Health \& Welfare, Korea.

\section{REFERENCES}

1. Kalashnikova LA, Zueva YV, Pugacheva OV, Korsakova NK. Cognitive impairments in cerebellar infarcts. Neurosci Behav Physiol 2005;35:773-9.

2. Glickstein M, Strata P, Voogd J. Cerebellum: history. Neuroscience 2009;162:549-59.

3. Schmahmann JD, Sherman JC. The cerebellar cognitive affective syndrome. Brain 1998;121(Pt 4):561-79.

4. O'Halloran CJ, Kinsella GJ, Storey E. The cerebellum and neuropsychological functioning: a critical review. J Clin Exp Neuropsychol 2012;34:35-56.

5. Gottwald B, Wilde B, Mihajlovic Z, Mehdorn HM. Evidence for distinct cognitive deficits after focal cerebellar lesions. J Neurol Neurosurg Psychiatry 2004;75:1524-31.

6. Hokkanen LS, Kauranen V, Roine RO, Salonen O, Kotila M. Subtle cognitive deficits after cerebellar infarcts. Eur J Neurol 2006;13:161-70.

7. Townsend J, Courchesne E, Covington J, Westerfield M, Harris NS, Lyden P, et al. Spatial attention deficits in patients with acquired or developmental cerebellar abnormality. J Neurosci 1999;19:5632-43.
8. Neau JP, Arroyo-Anllo E, Bonnaud V, Ingrand P, Gil R. Neuropsychological disturbances in cerebellar infarcts. Acta Neurol Scand 2000;102:363-70.

9. Lezak MD. Neuropsychological assessment. 4th ed. New York: Oxford University Press; 2004. p. 343-761.

10. Kang Y, Jang S, Na DL. Seoul Neuropsychological Screening Battery (SNSB-II). 2nd ed. Seoul: Human Brain Research \& Consulting Co.; 2012. p. 11-83.

11. Voogd J, Glickstein M. The anatomy of the cerebellum. Trends Neurosci 1998;21:370-5.

12. Schmahmann JD. From movement to thought: anatomic substrates of the cerebellar contribution to cognitive processing. Hum Brain Mapp 1996;4:174-98.

13. Diedrichsen J, Maderwald S, Kuper M, Thurling M, Rabe K, Gizewski ER, et al. Imaging the deep cerebellar nuclei: a probabilistic atlas and normalization procedure. Neuroimage 2011;54:1786-94.

14. Dimitrova A, Weber J, Redies C, Kindsvater K, Maschke M, Kolb FP, et al. MRI atlas of the human cerebellar nuclei. Neuroimage 2002;17:240-55.

15. Dimitrova A, Zeljko D, Schwarze F, Maschke M, Gerwig M, Frings M, et al. Probabilistic 3D MRI atlas of the human cerebellar dentate/interposed nuclei. Neuroimage 2006;30:12-25.

16. Schweizer TA, Alexander MP, Cusimano M, Stuss DT. Fast and efficient visuotemporal attention requires the cerebellum. Neuropsychologia 2007;45:3068-74.

17. Gottwald B, Mihajlovic Z, Wilde B, Mehdorn HM. Does the cerebellum contribute to specific aspects of attention? Neuropsychologia 2003;41:1452-60.

18. Leggio MG, Tedesco AM, Chiricozzi FR, Clausi S, Orsini A, Molinari M. Cognitive sequencing impairment in patients with focal or atrophic cerebellar damage. Brain 2008;131(Pt 5):1332-43.

19. Middleton FA, Strick PL. Anatomical evidence for cerebellar and basal ganglia involvement in higher cognitive function. Science 1994;266:458-61.

20. Leiner HC, Leiner AL, Dow RS. Reappraising the cerebellum: what does the hindbrain contribute to the forebrain? Behav Neurosci 1989;103:998-1008.

21. Arnsten AF, Rubia K. Neurobiological circuits regulating attention, cognitive control, motivation, and emotion: disruptions in neurodevelopmental psychiatric disorders. J Am Acad Child Adolesc Psychiatry 2012;51:356-67.

22. Middleton FA, Strick PL. Basal ganglia and cerebellar 
loops: motor and cognitive circuits. Brain Res Brain Res Rev 2000;31:236-50.

23. Petersen SE, Fiez JA. The processing of single words studied with positron emission tomography. Annu Rev Neurosci 1993;16:509-30.

24. Kim SG, Ugurbil K, Strick PL. Activation of a cerebellar output nucleus during cognitive processing. Science 1994;265:949-51.

25. Klingberg T, Roland P, Kawashima R. The neural correlates of the central executive function during working memory: a PET study. Hum Brain Mapp 1995; 1(Suppl 1):414.

26. Leblanc R, Meyer E, Bub D, Zatorre RJ, Evans AC. Language localization with activation positron emission tomography scanning. Neurosurgery 1992;31:369-73.

27. Leiner HC, Leiner AL, Dow RS. Does the cerebellum contribute to mental skills? Behav Neurosci 1986; 100:443-54.

28. Allen G, McColl R, Barnard H, Ringe WK, Fleckenstein J, Cullum CM. Magnetic resonance imaging of cerebellar-prefrontal and cerebellar-parietal functional connectivity. Neuroimage 2005;28:39-48.

29. Desmond JE, Gabrieli JD, Wagner AD, Ginier BL, Glover GH. Lobular patterns of cerebellar activation in verbal working-memory and finger-tapping tasks as revealed by functional MRI. J Neurosci 1997;17:967585.

30. Chen SH, Desmond JE. Temporal dynamics of cerebro-cerebellar network recruitment during a cognitive task. Neuropsychologia 2005;43:1227-37.
31. Molinari M, Leggio MG, Silveri MC. Verbal fluency and agrammatism. Int Rev Neurobiol 1997;41:325-39.

32. Linde L, Bergstrom M. The effect of one night without sleep on problem-solving and immediate recall. Psychol Res 1992;54:127-36.

33. Schmahmann JD, Macmore J, Vangel M. Cerebellar stroke without motor deficit: clinical evidence for motor and non-motor domains within the human cerebellum. Neuroscience 2009;162:852-61.

34. Tatu L, Moulin T, Bogousslavsky J, Duvernoy H. Arterial territories of human brain: brainstem and cerebellum. Neurology 1996;47:1125-35.

35. Elizabeth O, Molliver ME. Organizational principles and microcircuitry of the cerebellum. Int Rev Psychiatry 2001;13:232-46.

36. Rudrauf D, Mehta S, Bruss J, Tranel D, Damasio H, Grabowski TJ. Thresholding lesion overlap difference maps: application to category-related naming and recognition deficits. Neuroimage 2008;41:970-84.

37. Rorden C, Karnath HO. Using human brain lesions to infer function: a relic from a past era in the fMRI age? Nat Rev Neurosci 2004;5:813-9.

38. D'Angelo E, De Zeeuw CI. Timing and plasticity in the cerebellum: focus on the granular layer. Trends Neurosci 2009;32:30-40.

39. Malm J, Kristensen B, Karlsson T, Carlberg B, Fagerlund $\mathrm{M}$, Olsson T. Cognitive impairment in young adults with infratentorial infarcts. Neurology 1998;51: 433-40. 